\title{
BIOCATALYTIC CHARACTERIZATION OF HUMAN FMO5: UNEARTHING BAEYER-VILLIGER REACTIONS IN HUMANS
}

\author{
Filippo Fiorentini $^{\mathrm{a}, \mathrm{b}}$, Martina Geier ${ }^{\mathrm{b}}$, Claudia Binda ${ }^{\mathrm{a}}$, Margit Winkler ${ }^{\mathrm{b}}$, Kurt Faber ${ }^{\mathrm{c}}$, \\ Mélanie Hall ${ }^{\mathrm{c}, *}$, Andrea Mattevi ${ }^{\mathrm{a}, *}$
}

${ }^{a}$ Department of Biology and Biotechnology, University of Pavia, via Ferrata 9, 27100 Pavia, Italy

${ }^{b}$ Austrian Centre of Industrial Biotechnology, c/o Institute of Molecular Biotechnology, Graz University of Technology, Petersgasse 14, 8010 Graz, Austria

${ }^{\mathrm{c}}$ Department of Chemistry, University of Graz, Heinrichstrasse 28, $8010 \mathrm{Graz}$, Austria.

*Correspondence to: Andrea Mattevi (andrea.mattevi@unipv.it) or Mélanie Hall (melanie.hall@uni-graz.at)

\section{SUPPORTING INFORMATION}

1. Table S1 listing of soft-nucleophiles compounds not converted by hFMO5 and comparison with known FMO substrates (p.2)

2. Table $\mathrm{S} 2$ reporting multiple sequence alignment of hFMO5 fingerprint motifs with canonical FMO and BVMO proteins (p.3)

3. Analytical methods for conversion determination and quantification (p.4)

4. GC traces (for 19a HPLC trace) for all compounds (p.6)

5. GC-MS traces (p.18)

6. Protocol for synthesis of $22 \mathrm{~b}$ according to standard procedures (p.26) 


\section{Table S1. List of soft-nucleophile compounds not converted by hFMO5 and comparison with known FMO substrates}

The table reports the list of tested compounds bearing typical FMO-mediated oxygenation sites (soft-nucleophilic heteroatoms; see reference 1) which were not converted by hFMO5 in our assays.

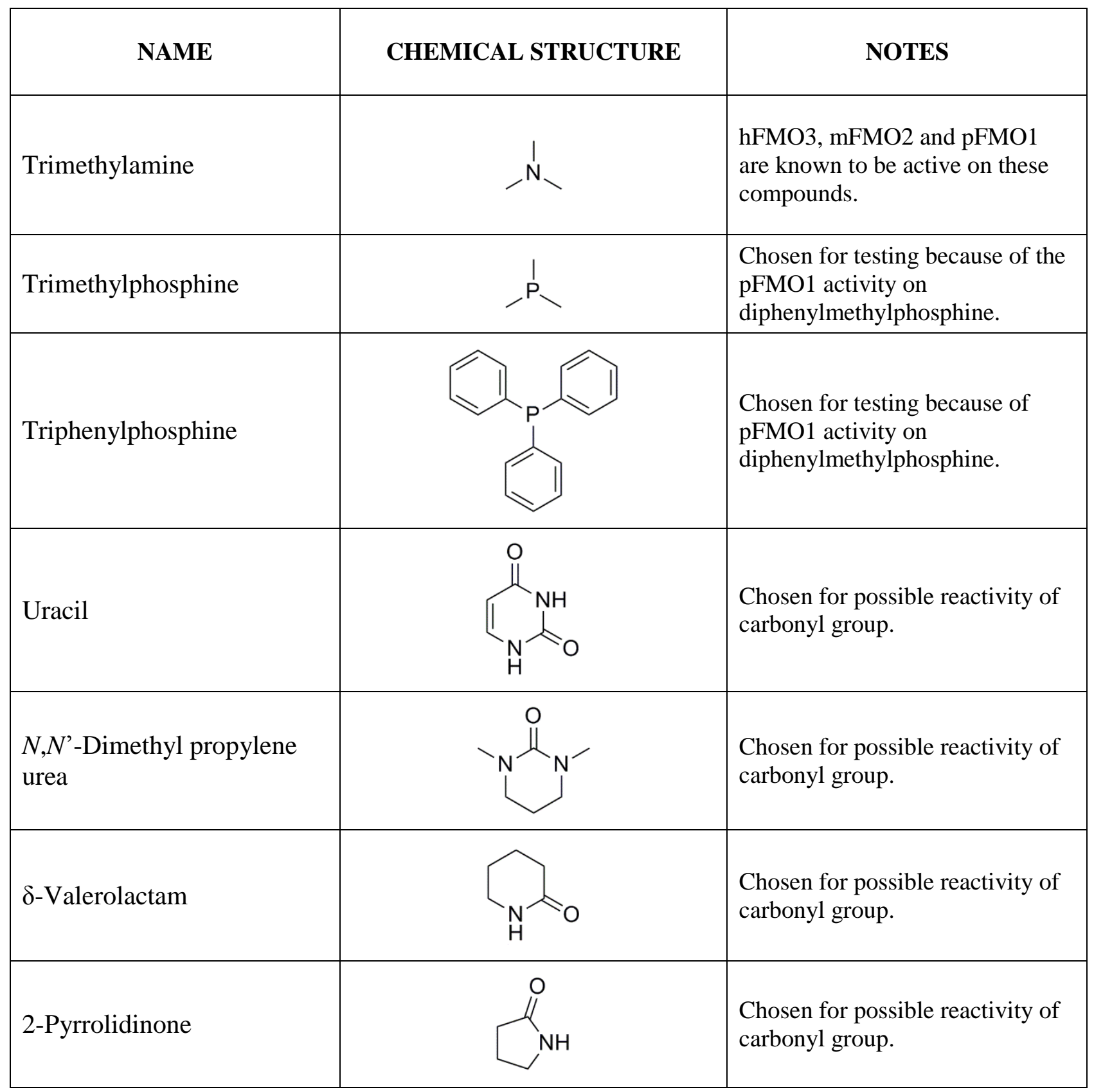

pFMO = pig FMO; mFMO = mouse FMO; hFMO = human FMO 


\section{Table S2. Multiple sequence alignment of hFMO5 fingerprint motifs with canonical FMO and BVMO proteins}

The table reports CLUSTAL O(1.2.1) multiple sequence alignment focused on monooxygenase specific motifs of hFMO5 with the other human FMOs (hFMO1-4), bacterial FMOs with BaeyerVilliger reported activity ${ }^{2,3}$ (Rhodococcus jostii FMO-E-G) and canonical BVMO proteins (Acinetobacter calcoaceticus cyclohexanone monooxygenase, acCHMO1; Thermobifida fusca phenylacetone monooxygenase, thPAMO). The specific FMO fingerprint motif (FxGxxxHxxxYK/R) is highlighted in blue, whereas the specific BVMO fingerprint motif $(F x G x x x H x x x W P / D)$ is highlighted in green $^{1-4}$.

\begin{tabular}{|c|c|c|c|c|c|}
\hline MONOOXYGENASE & $\begin{array}{c}\text { ACCESSION } \\
\text { NUMBER }\end{array}$ & $\begin{array}{l}\text { ROSSMANN } \\
\text { MOTIF } \\
\text { (FAD- } \\
\text { DOMAIN) }\end{array}$ & $\begin{array}{c}\text { SPECIFIC } \\
\text { FINGERPRINT } \\
\text { MOTIF }\end{array}$ & $\begin{array}{l}\text { ROSSMANN } \\
\text { MOTIF } \\
\text { (NADP- } \\
\text { DOMAIN) }\end{array}$ & $\begin{array}{c}\text { IDENTITY } \\
\text { WITH } \\
\text { hFMO5 } \\
(\%)\end{array}$ \\
\hline hFMO5 & Z47553 & GxGxxG & FxGxxxHxxxYK & GxGxxG & \\
\hline hFMO1 & Q01740 & GxGxxG & FxGxxxHxxxYK & GxGxxG & 51 \\
\hline hFMO2 & Q99518 & GxGxxG & FxGxxxHxxxYK & GxGxxG & 58 \\
\hline hFMO3 & P31513 & GxGxxG & FxGxxxHxxxYK & GxGxxG & 56 \\
\hline hFMO4 & P31512 & GxGxxG & FxGxxxHxxxYK & GxGxxG & 54 \\
\hline rhFMO-E & RO00824 & GxGxxG & $\mathbf{F x G \times x \times H \times x x Y D}$ & GxGxxA & 23 \\
\hline rhFMO-F & RO04244 & GxGxxG & $\mathbf{F x G \times x \times H \times x x H P}$ & GxNxxA & 24 \\
\hline rhFMO-G & RO05696 & GxGxxG & 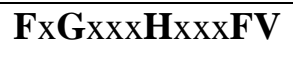 & $\mathrm{GxCxxG}$ & 24 \\
\hline acCHMO1 & BAA86293 & GxGxxG & FxGxxxHxxxWP & GxGxxG & 27 \\
\hline thPAMO & Q47PU3 & GxGxxG & FxGxxxHxxxWP & GxGxxG & 27 \\
\hline
\end{tabular}




\section{Analytical methods for conversion determination and quantification}

GC-MS measurements were carried out on a 7890A GC System (Agilent Technologies, Santa Clara, CA, USA), equipped with a 5975C mass selective detector and an HP-5MS column (5\% phenylmethylsiloxane, $30 \mathrm{~m}$ x $0.20 \mathrm{~mm}$ x $0.25 \mu \mathrm{m}$, J\&W Scientific, Agilent Technologies) using $\mathrm{He}$ as carrier gas. Conversions were obtained from measurements on an Agilent Technologies 7890 A GC system equipped with a FID-detector and a 7693 autosampler by using $\mathrm{H}_{2}$ as carrier gas and a 5\% phenylmethylpolysiloxane capillary column (J\&W HP-5, $30 \mathrm{~m}, 0.32 \mathrm{~mm}$ ID, 0.25 $\mu \mathrm{m}$ film). 1-Decanol or $(R)$-limonene was used as internal standard (10 $\mathrm{mM}$ in ethyl acetate). Samples were injected with a split ratio of 50:1. Enantiomeric excesses were calculated from measurements on an Agilent Technologies 7890 A GC system equipped with a FID-detector and a 7683B Injector in combination with a 7683 Series Autosampler by using $\mathrm{H}_{2}$ as carrier gas and either a Chirasil Chiraldex DEX-CB (25 m x $0.32 \mathrm{~mm}, 0.25 \mu \mathrm{m}$ film) column (A) or a MachereyNagel Hydrodex- $\beta$-TBDAc (50 m x $0.40 \mathrm{~mm}$ x $0.25 \mathrm{~mm}$ ID) column (B). Absolute configurations and product identity were assigned by co-injection with authentic reference materials, comparison of retention times and elution orders with literature data (under identical experimental conditions). For HPLC analysis, a Shimadzu LC-20AD HPLC system with a DGU20A5 degasser, a SIL-20AC autosampler, SPD-M20A diode array detector and a CTO-20AC column oven was used. Conversions of all substrates (except of 19a) were determined by GCFID. Temperature injector: $250{ }^{\circ} \mathrm{C}$, temperature detector: $250{ }^{\circ} \mathrm{C}$, temperature program: $60{ }^{\circ} \mathrm{C}$, hold for $0.5 \mathrm{~min}, 10{ }^{\circ} \mathrm{C} / \mathrm{min}$ to $200{ }^{\circ} \mathrm{C}$, hold for $0 \mathrm{~min}, 20{ }^{\circ} \mathrm{C} / \mathrm{min}$ to $280{ }^{\circ} \mathrm{C}$, hold for $2 \mathrm{~min}$; retention times: 1a $3.09 \mathrm{~min}, \mathbf{1 b} 6.18 \mathrm{~min}$; 2a $2.07 \mathrm{~min}, \mathbf{2 b} 2.27 \mathrm{~min}$; 3a $1.34 \mathrm{~min}$, 3b $1.48 \mathrm{~min}$; 4a 2.07 min, 4b 2.19 min, 4c 2.26 min; 5a 0.86 min, 5b 0.91 min, 5c 0.94 min; 6a 1.23 min, 6b 1.38 min; 7a 0.78 min, 7b 0.79 min; 8a 1.07 min, 8b 0.94 min; 9a 3.63 min, 9b 4.10 min; 10a

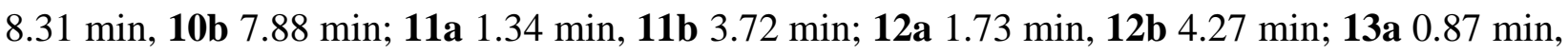
13b 2.72 min; 14a 3.90 min, 14b 6.73 min; 15a 9.05 min, 15b 11.60 min; 16a 0.87 min, 16b 2.72 min; 17a 1.06 min, 17b 3.18 min, 17c 3.13 min; 18a 1.11 min, 18b 3.38 min, 18c 3.29 min; 20a 5.10 and $5.50 \mathrm{~min}$; 21a $3.66 \mathrm{~min}, 22 \mathrm{a} 1.18 \mathrm{~min}, 22 \mathrm{~b} 1.24 \mathrm{~min}$. Conversion of 19a was determined by HPLC using a Phenomenex Luna C18(2) $(25 \mathrm{~cm}$ x $0.46 \mathrm{~cm})$. Conditions: Flow: 1 $\mathrm{ml} / \mathrm{min}, 25^{\circ} \mathrm{C}$, solvent A: $\mathrm{H}_{2} \mathrm{O}$, solvent B: MeCN, solvent B 0\% 0-15 min, B 40\% 15-20 min, B 100\% 20-22 min, B 0\% 22-30 min. Retention times: 19a 19.75 min, 19b 18.25 min. Enantiomeric excesses were calculated from measurements on column A for compounds 7a, 13a 
and on column B for compounds 12a, 15a, 17a, 18a. For 7a: temperature injector: $230{ }^{\circ} \mathrm{C}$, temperature detector: $250{ }^{\circ} \mathrm{C}$, temperature program: $40{ }^{\circ} \mathrm{C}$, hold for $2 \mathrm{~min}, 2{ }^{\circ} \mathrm{C} / \mathrm{min}$ to $70{ }^{\circ} \mathrm{C}$, hold for $0 \mathrm{~min}, 10^{\circ} \mathrm{C} / \mathrm{min}$ to $180{ }^{\circ} \mathrm{C}$, hold for $2 \mathrm{~min}$; retention times: $(R / S)-7 \mathbf{a} 8.36 \mathrm{~min},(R / S)-7 \mathbf{a}$ $8.67 \mathrm{~min},(R / S)-7 \mathbf{b} 7.72 \mathrm{~min},(R / S)-7 \mathbf{b} 9.22 \mathrm{~min}$. For 13a: temperature injector: $230{ }^{\circ} \mathrm{C}$, temperature detector: $250{ }^{\circ} \mathrm{C}$, temperature program: $45^{\circ} \mathrm{C}$, hold for $2 \mathrm{~min}, 5{ }^{\circ} \mathrm{C} / \mathrm{min}$ to $65{ }^{\circ} \mathrm{C}$, hold for $25 \mathrm{~min}, 20^{\circ} \mathrm{C} / \mathrm{min}$ to $180{ }^{\circ} \mathrm{C}$, hold for $2 \mathrm{~min}$; retention times: $(R)-13 \mathbf{a} 23.46 \mathrm{~min},(S)-13 \mathbf{a}$ $23.82 \mathrm{~min},(R)-\mathbf{1 3 b} 36.53 \mathrm{~min},(S)$-13b $36.49 \mathrm{~min}$. For 12a: temperature injector: $230{ }^{\circ} \mathrm{C}$, temperature detector: $250{ }^{\circ} \mathrm{C}$, temperature program: $120^{\circ} \mathrm{C}$, hold for $2 \mathrm{~min}, 2{ }^{\circ} \mathrm{C} / \mathrm{min}$ to $180{ }^{\circ} \mathrm{C}$, hold for 5 min; retention times: $(R)-\mathbf{1 2 a} 6.43 \mathrm{~min},(S)$-12a $6.54 \mathrm{~min},(R)-\mathbf{1 2 b} 21.41 \mathrm{~min},(S)-\mathbf{1 2 b}$ 19.95 min. For 15a: temperature injector: $230{ }^{\circ} \mathrm{C}$, temperature detector: $250{ }^{\circ} \mathrm{C}$, temperature program: $80{ }^{\circ} \mathrm{C}$, hold for $0 \mathrm{~min}, 10{ }^{\circ} \mathrm{C} / \mathrm{min}$ to $110{ }^{\circ} \mathrm{C}$, hold for $0 \mathrm{~min}, 1{ }^{\circ} \mathrm{C} / \mathrm{min}$ to $210{ }^{\circ} \mathrm{C}$, hold for $0 \mathrm{~min}$; retention times: $(R)-\mathbf{1 5 a} 53.12 \mathrm{~min},(S)-\mathbf{1 5 a} 53.44 \mathrm{~min},(R)-\mathbf{1 5 b} 78.27 \mathrm{~min},(S)-\mathbf{1 5 b}$ $78.49 \mathrm{~min}$. For 17a and 18a: temperature injector: $230{ }^{\circ} \mathrm{C}$, temperature detector: $250{ }^{\circ} \mathrm{C}$, temperature program: $120{ }^{\circ} \mathrm{C}$, hold for $2 \mathrm{~min}, 2{ }^{\circ} \mathrm{C} / \mathrm{min}$ to $180{ }^{\circ} \mathrm{C}$, hold for $5 \mathrm{~min}$; retention times: $(R)-\mathbf{1 7 a} 6.22 \mathrm{~min},(S)-\mathbf{1 7 a} 6.04 \mathrm{~min},(R)-\mathbf{1 7 b} 25.03 \mathrm{~min},(S)-\mathbf{1 7 b} 25.85 \mathrm{~min},(R / S)-17 \mathbf{c}$ $24.18 \mathrm{~min}$; $(R)$-18a $7.52 \mathrm{~min},(S)$-18a $7.45 \mathrm{~min},(R)-\mathbf{1 8 b} 30.92 \mathrm{~min},(S)-\mathbf{1 8 b} 30.27 \mathrm{~min},(R)-\mathbf{1 8 c}$ $32.42 \mathrm{~min},(S)-\mathbf{1 8 c} 32.20 \mathrm{~min}$. 


\section{GC traces (for 19a HPLC trace) for all compounds}

Traces include overlay with corresponding references and blanks where specified.

Colour codes identical for all chromatograms:

- $\quad$ red $=$ FMO5 reaction

- blue $=$ commercially available reference 1

- $\quad$ light blue = commercially available reference 2

- $\quad$ green $=$ reaction with $\mathrm{CHMO}$

- $\quad$ violet $=$ reaction with $\mathrm{CPMO}$

- $\quad$ black $=$ FMO5 reaction with enantiopure $(R)$-3-methyl-cyclopentanone/hexanone

- $\quad$ brown = blank

- $\quad$ magenta $=\mathrm{H}_{2} \mathrm{O}_{2}$ control (performed for compounds 3a and 10a)
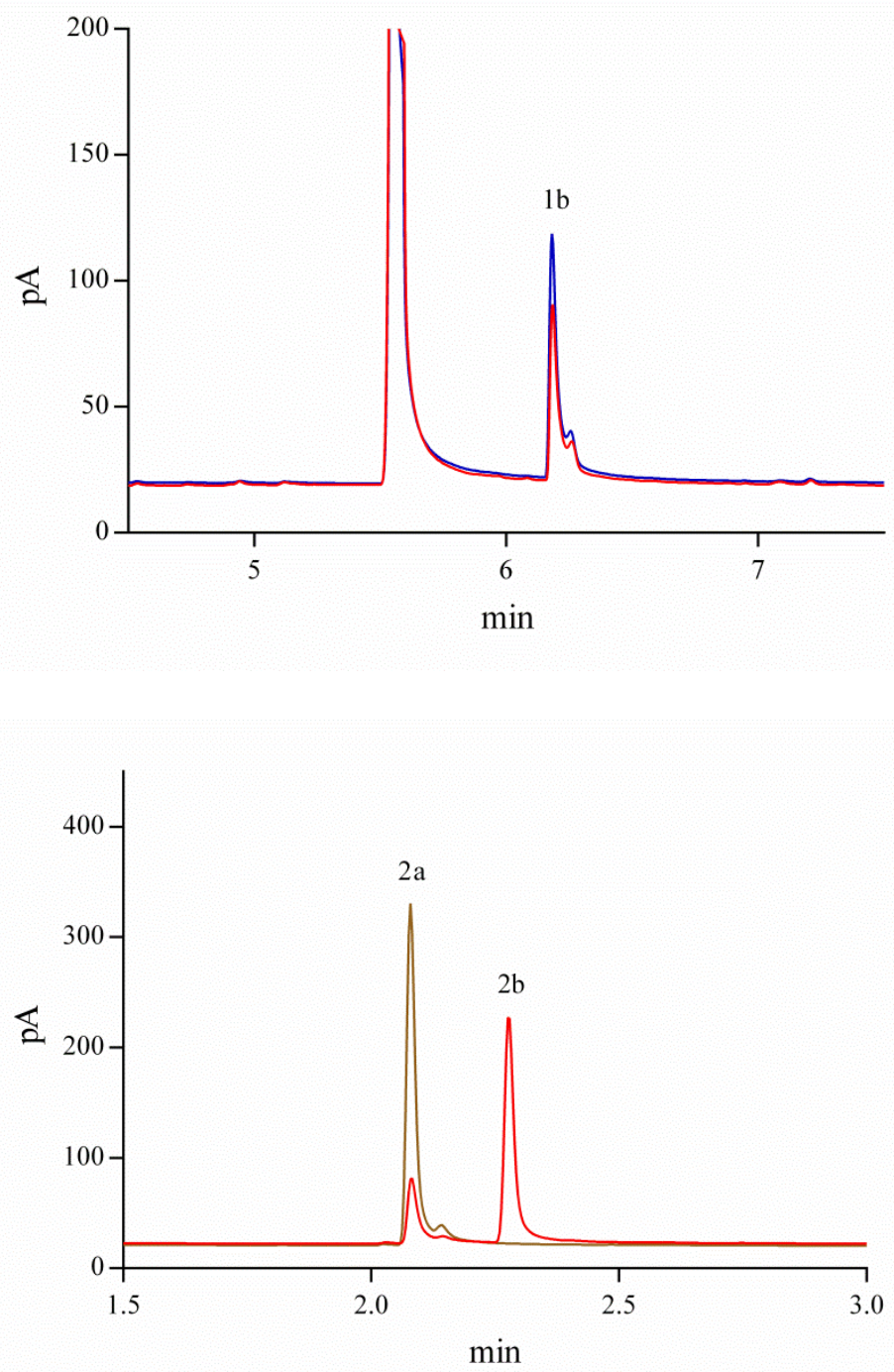

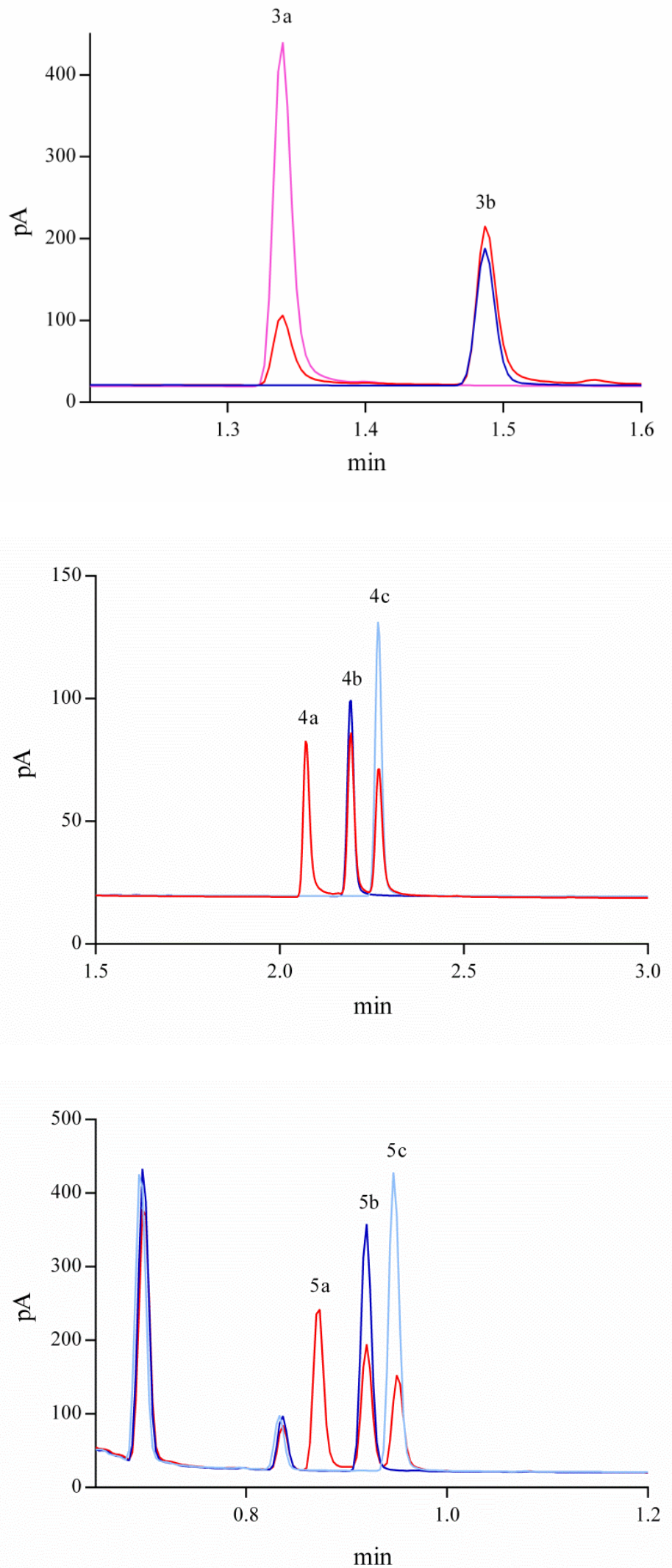

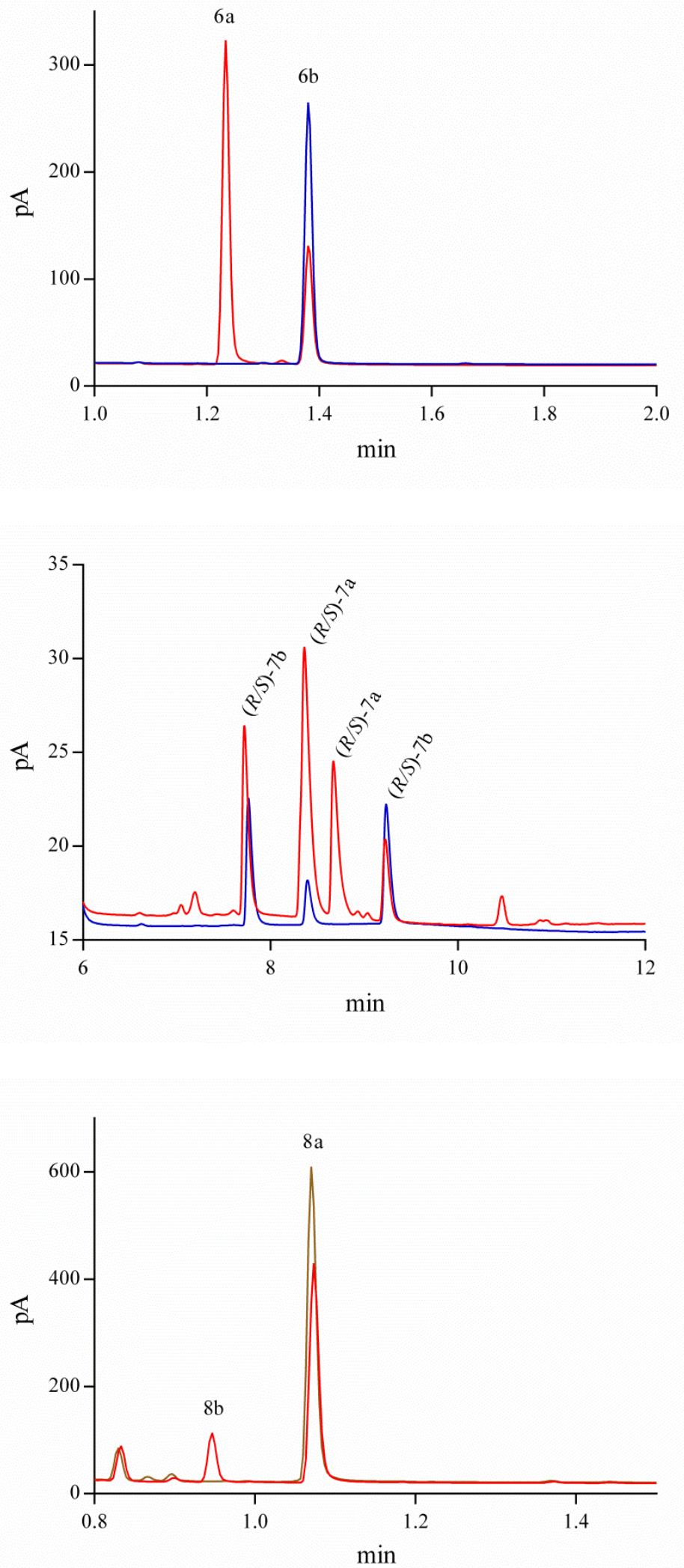

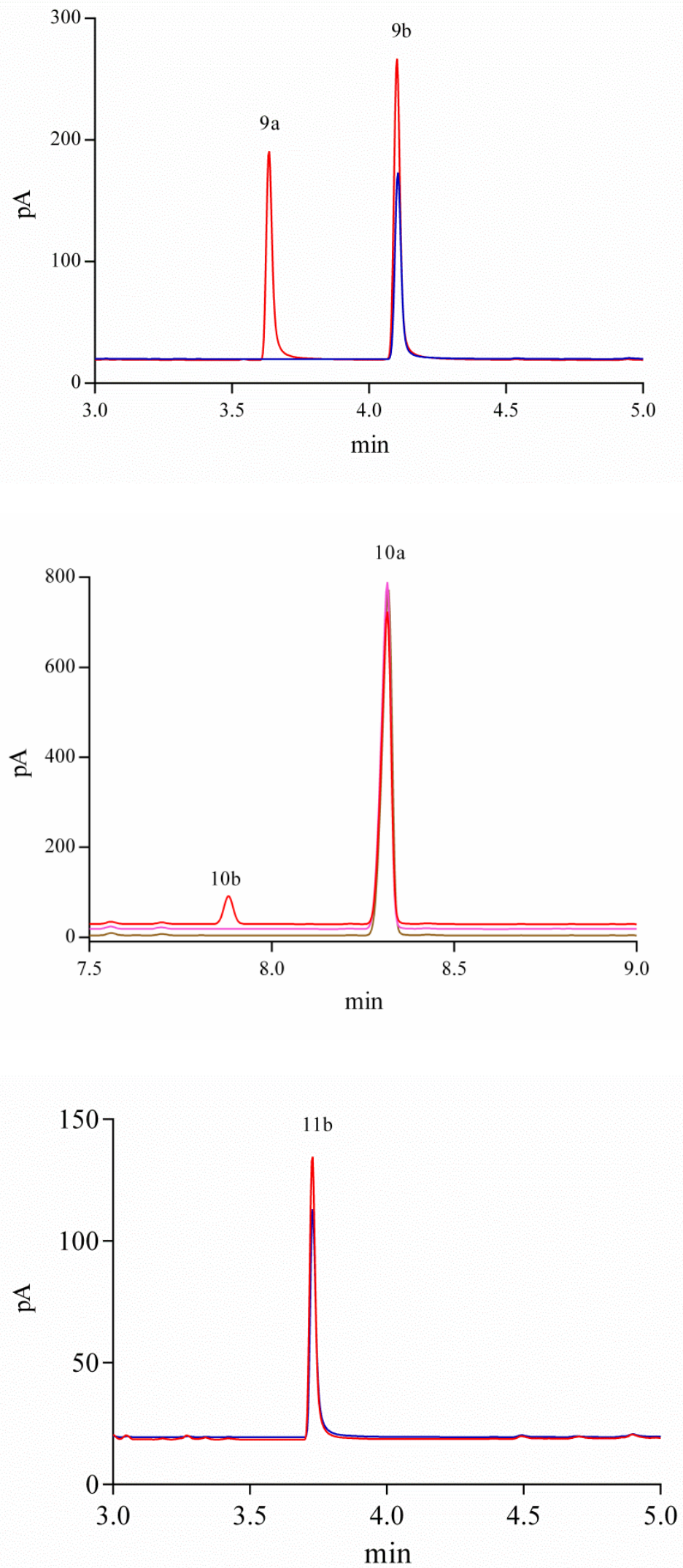

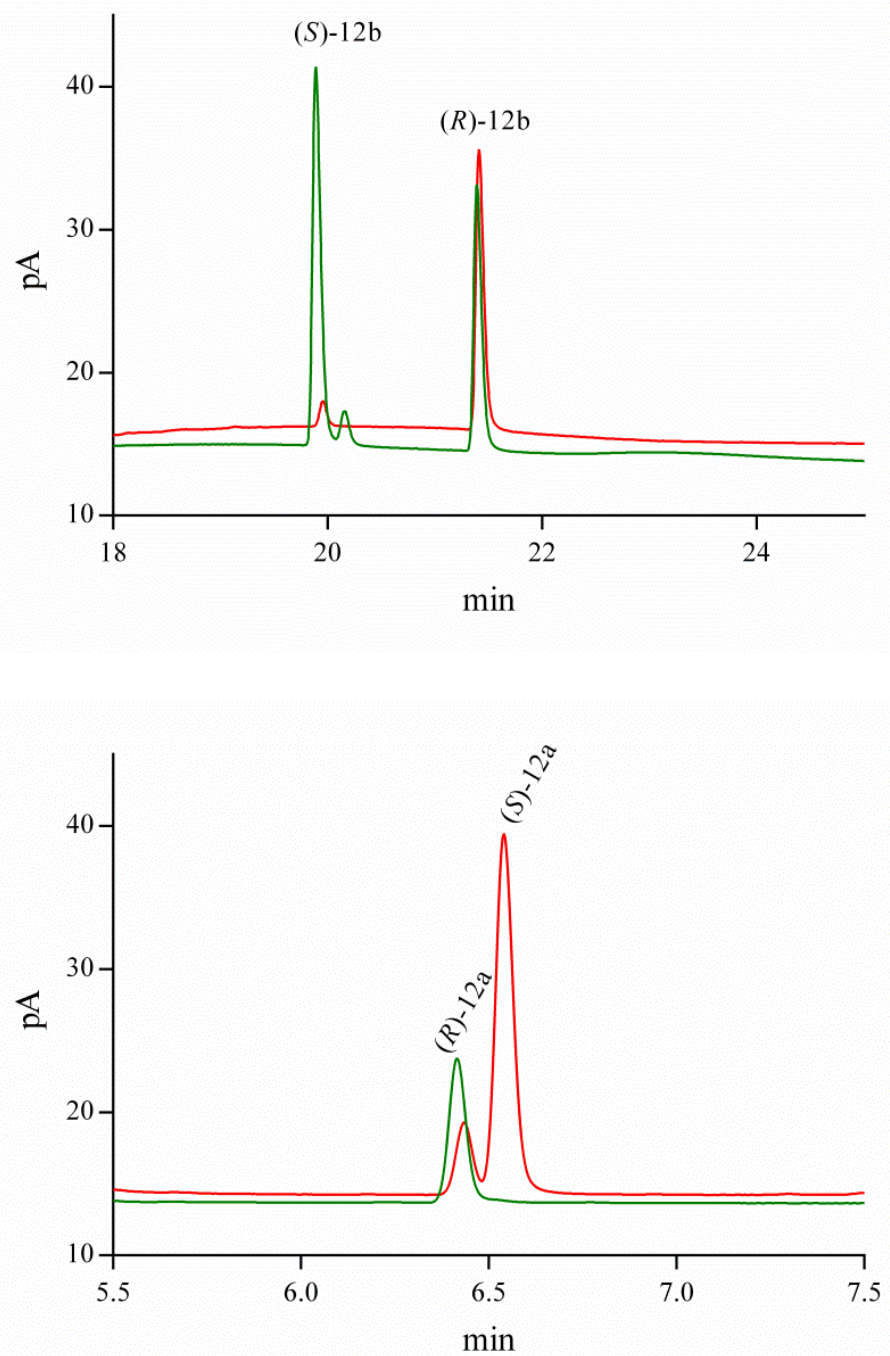

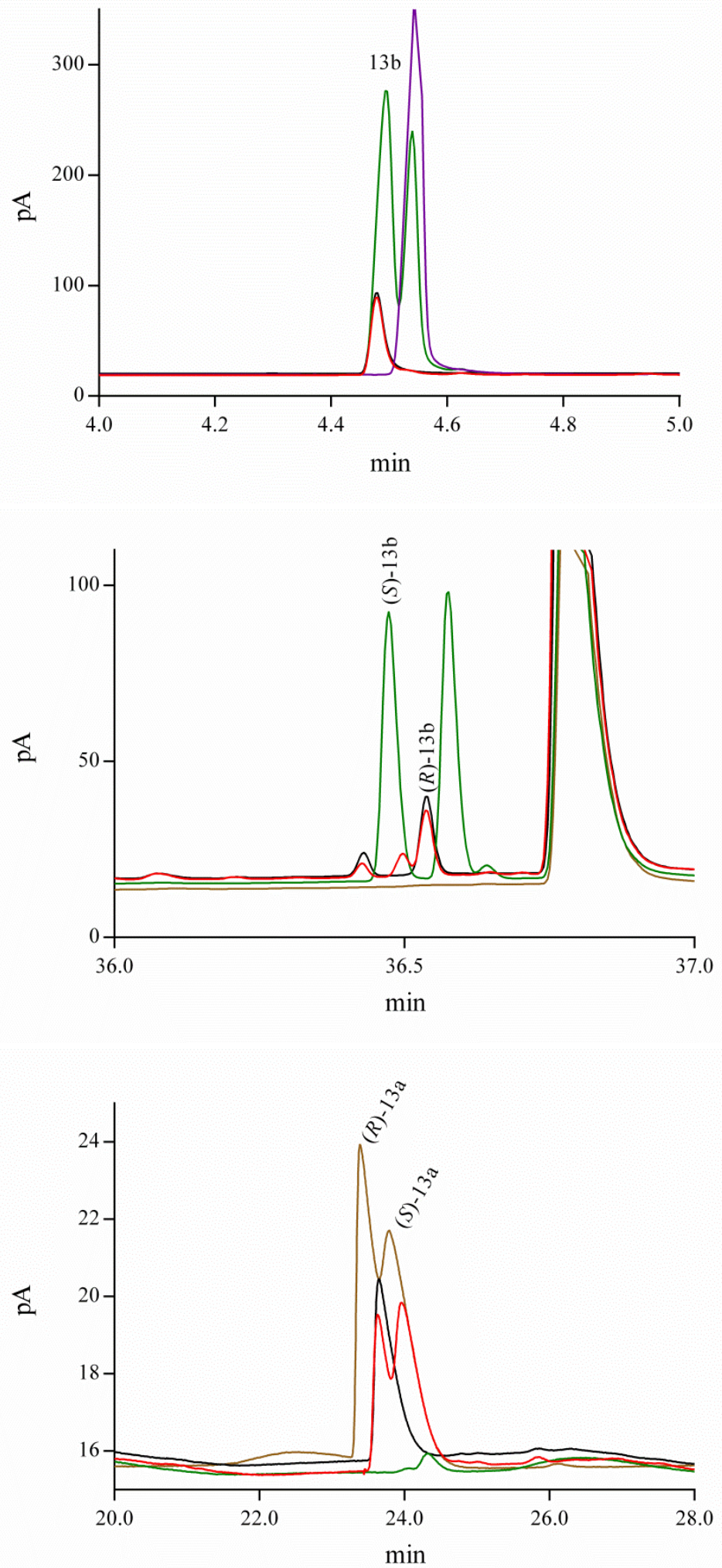

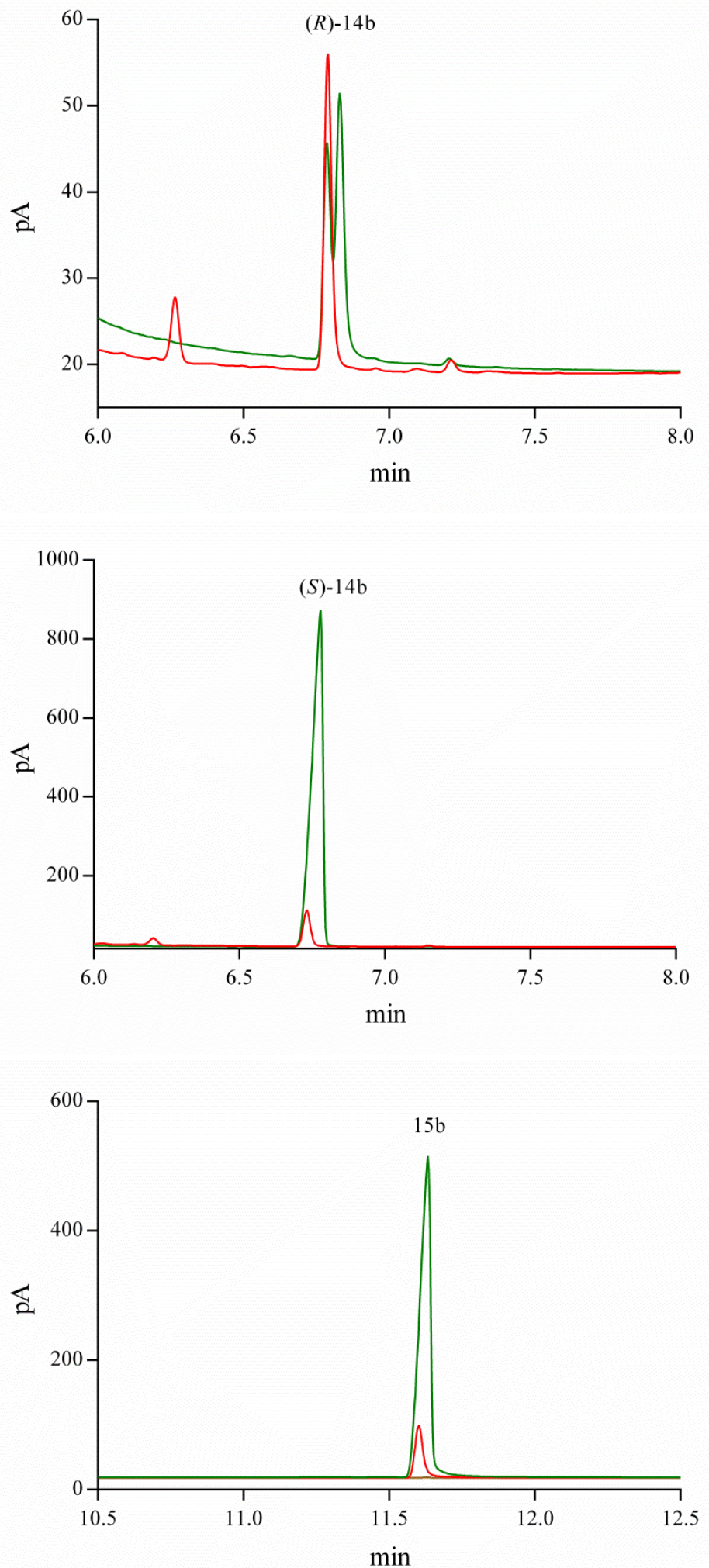

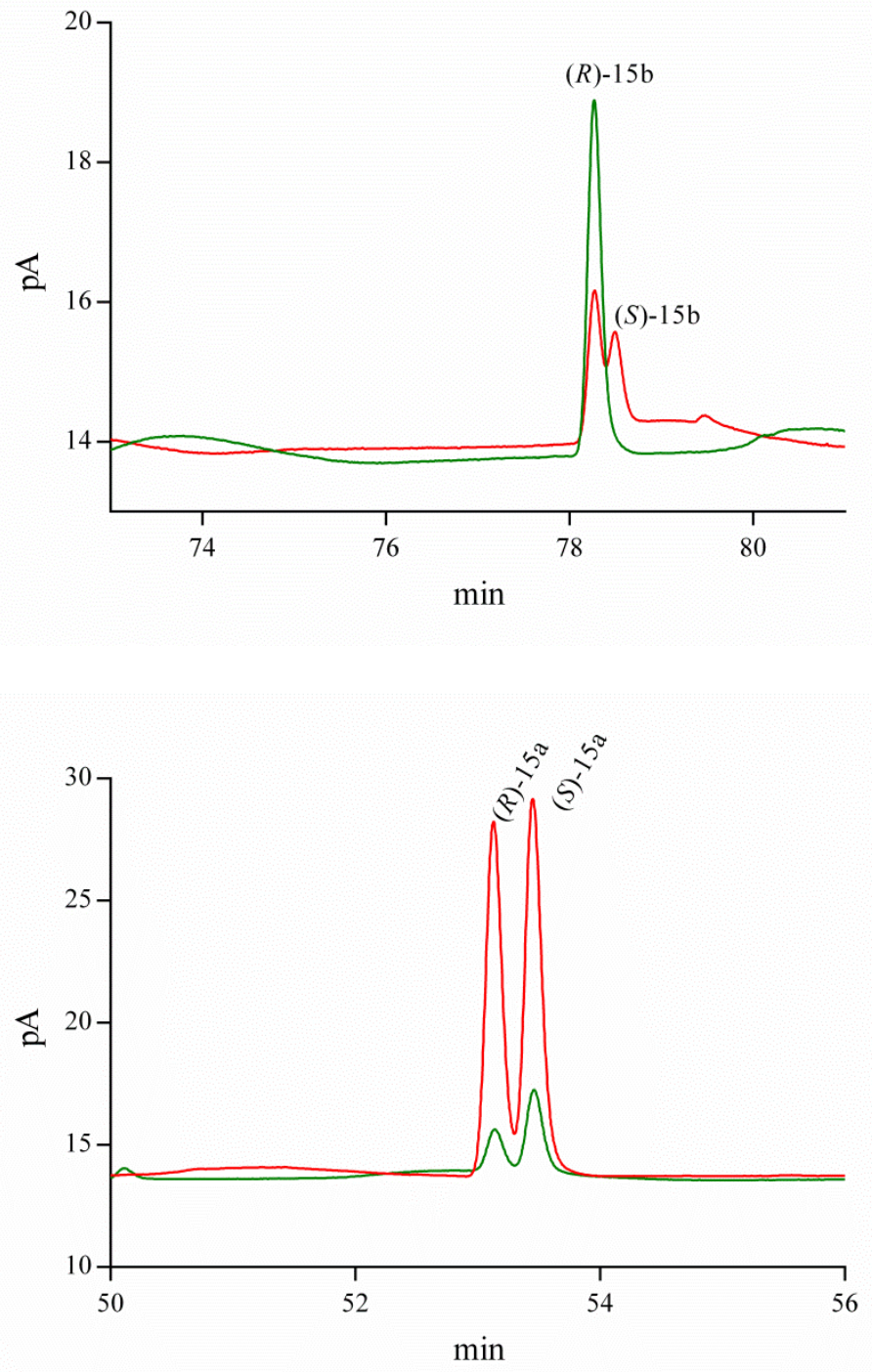

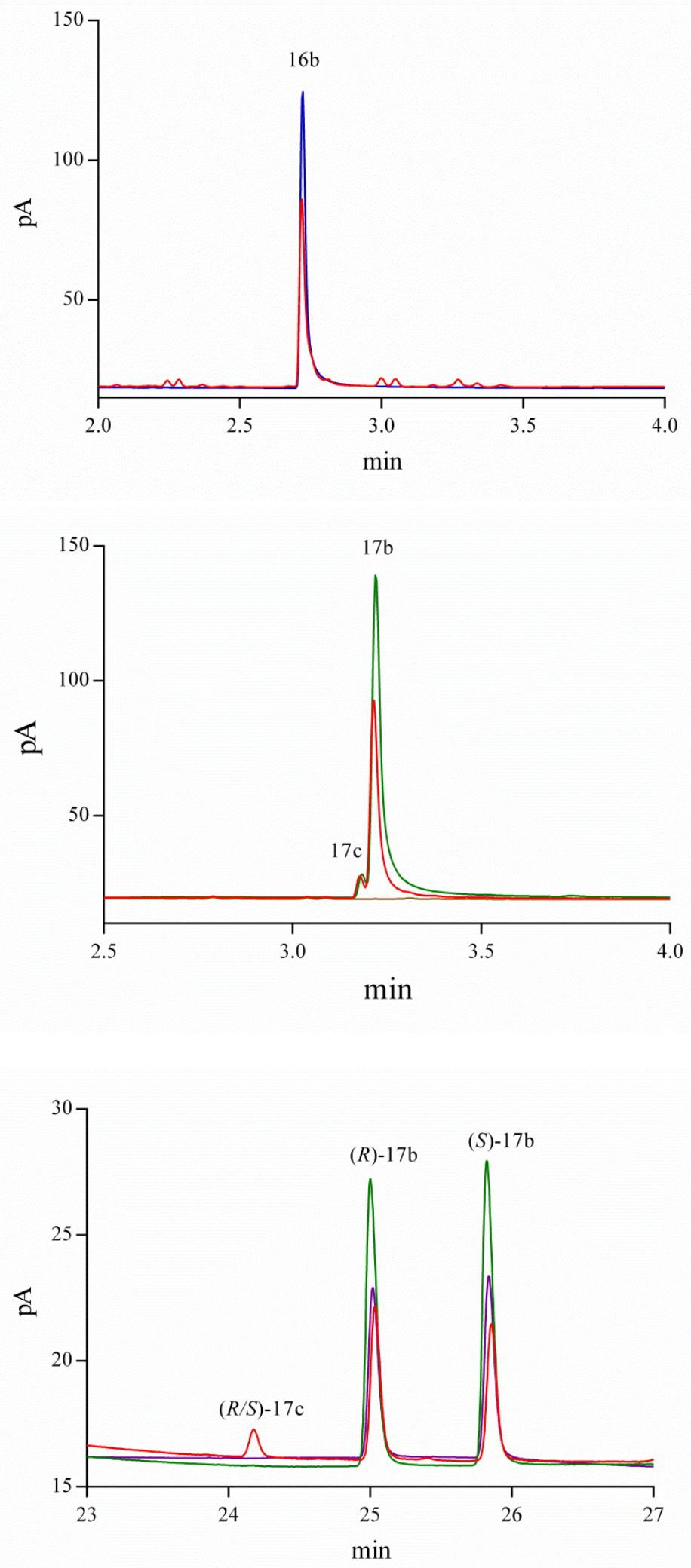

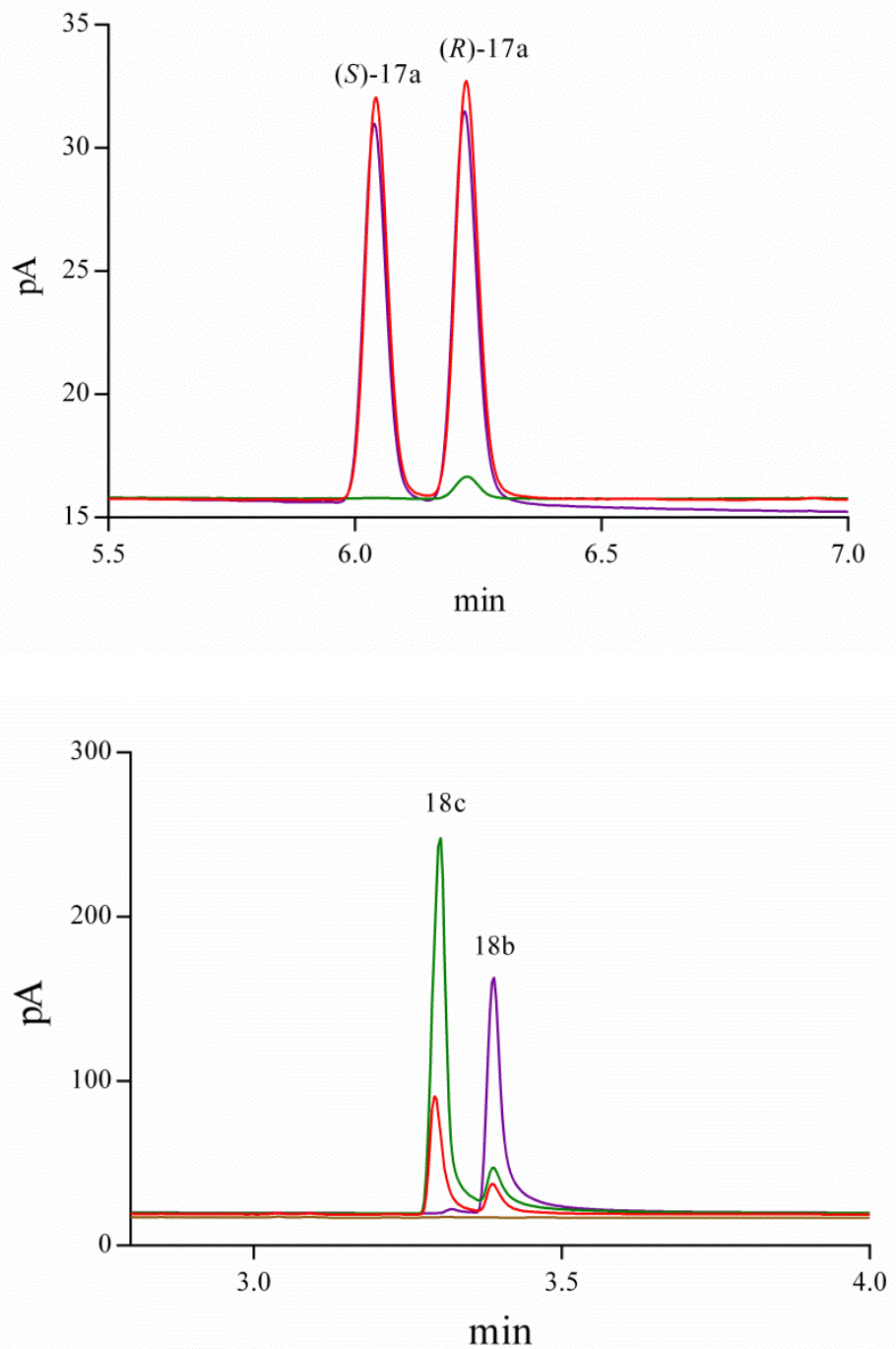

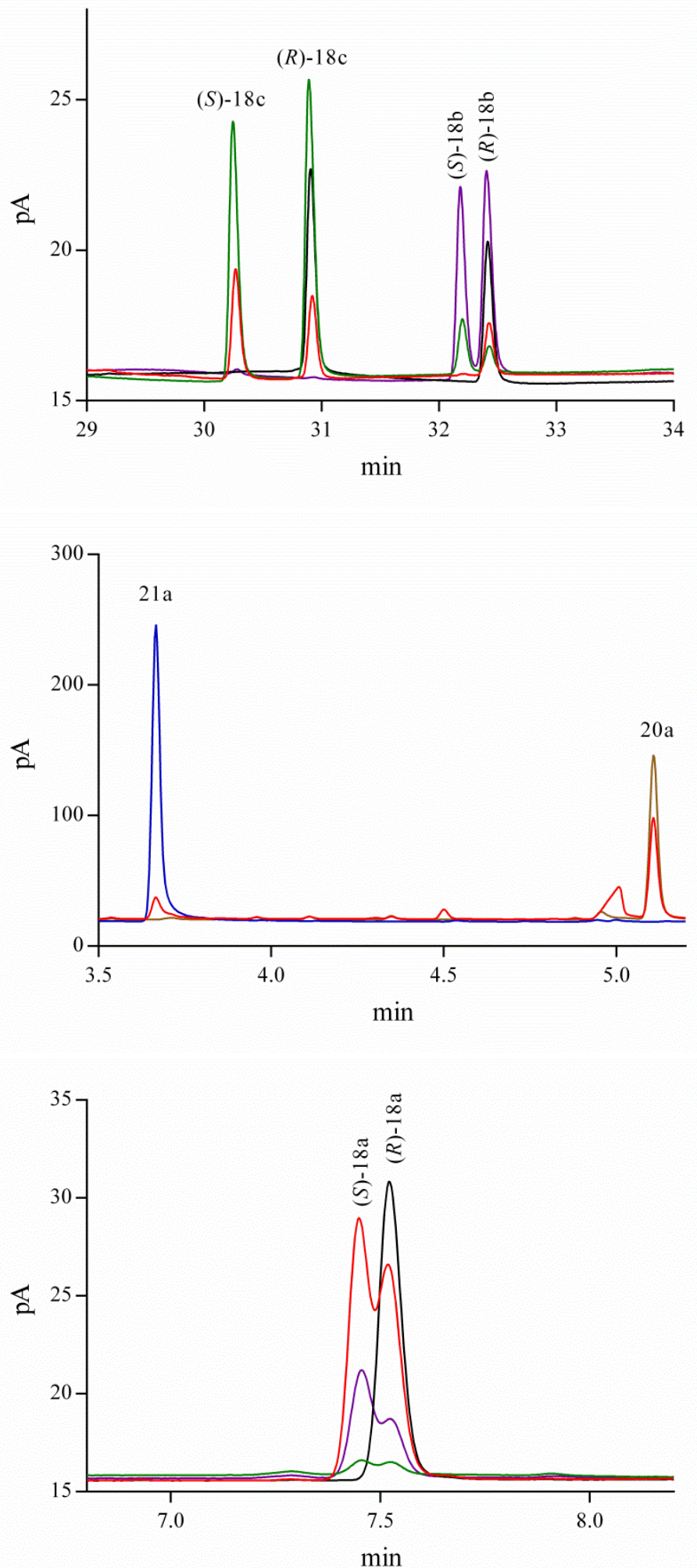

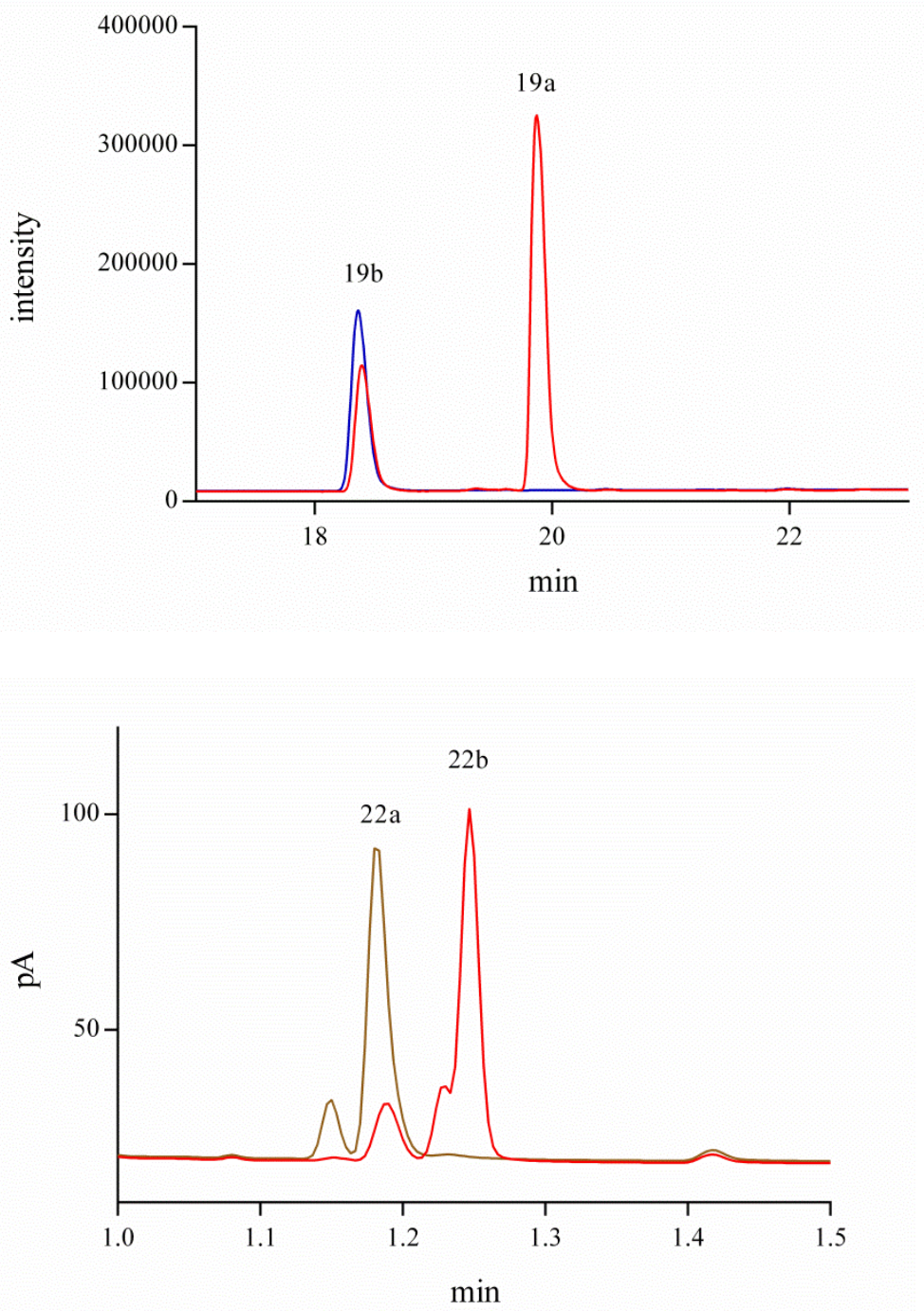


\section{GC-MS traces}
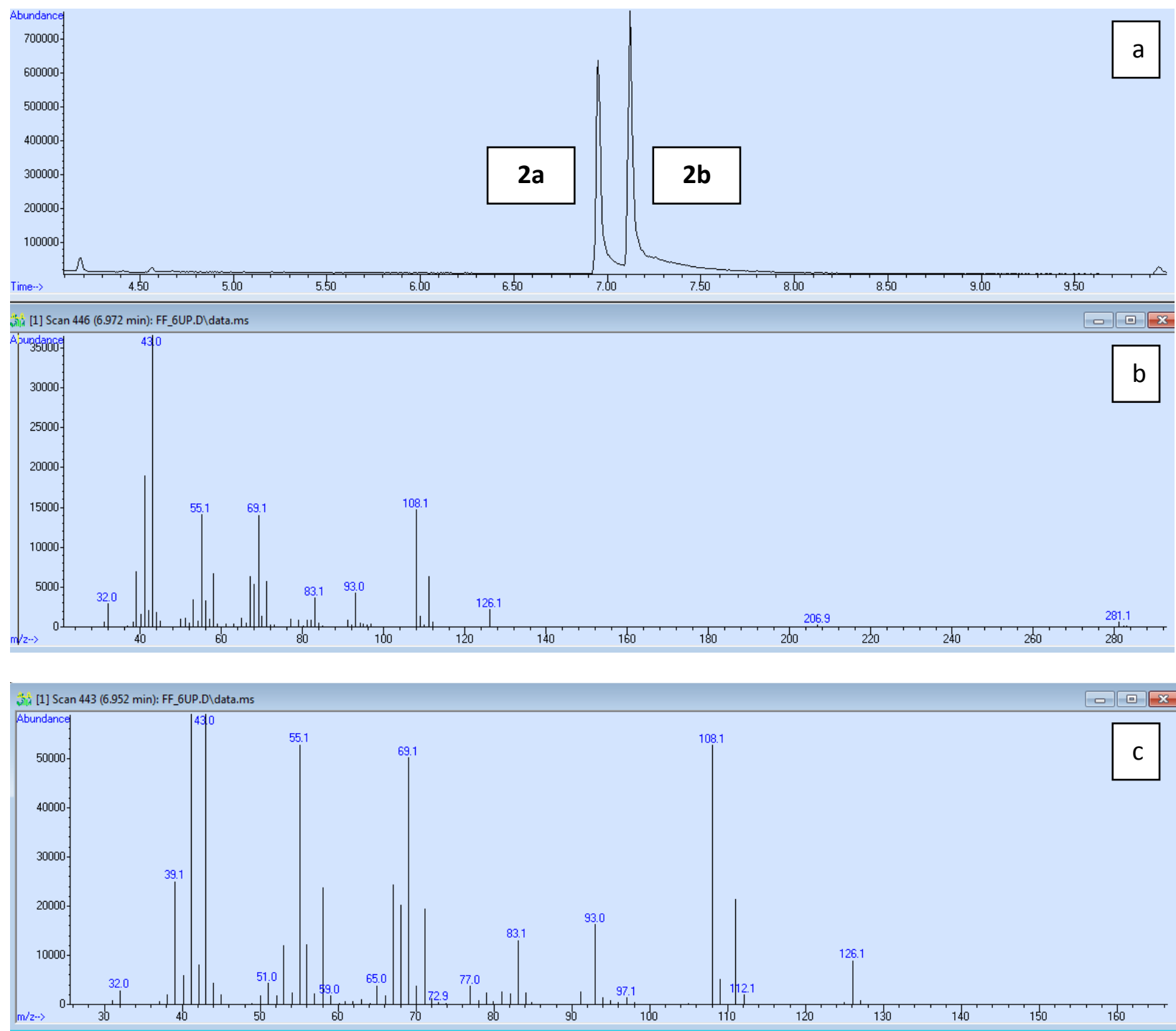

Spectrum from GC-MS measurement of sample from conversion of 2a. Panel a: GC trace with 2a (retention time: $6.9 \mathrm{~min}$ ) and $\mathbf{2 b}$ (retention time: $7.1 \mathrm{~min}$ ). Panel b: MS fragmentation pattern of 2a (MW 126 g.mol ${ }^{-1}$ ). Panel c: zoom-in of MS fragmentation pattern of $\mathbf{2 a}$ with absence of relevant peak for $\mathbf{2 b}$ (fragment 99). 

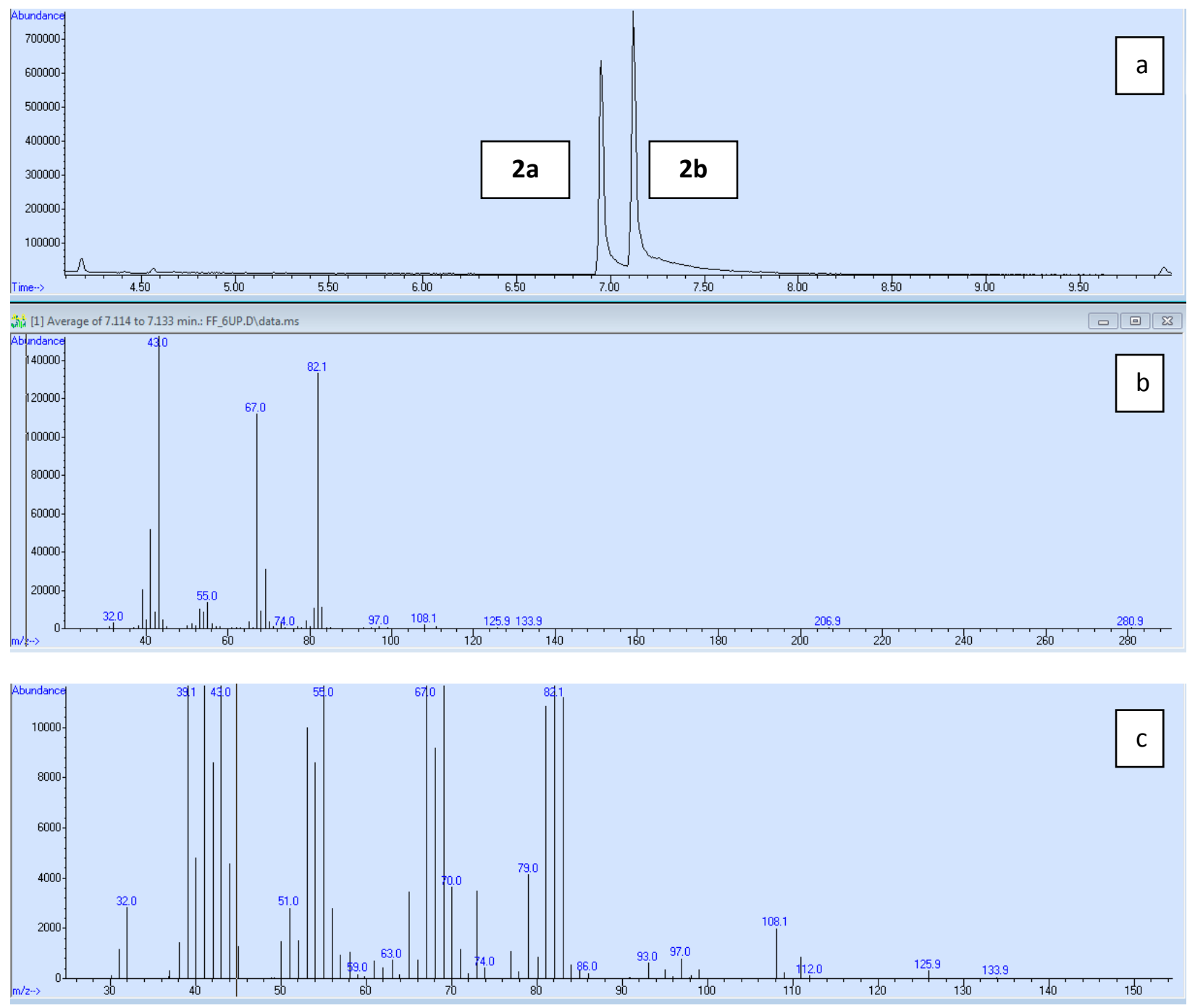

Spectrum from GC-MS measurement of sample from conversion of 2a. Panel a: GC trace with 2a (retention time: $6.9 \mathrm{~min}$ ) and $\mathbf{2 b}$ (retention time: $7.1 \mathrm{~min}$ ). Panel b: MS fragmentation pattern of 2a $\left(\right.$ MW 126 g.mol $\left.{ }^{-1}\right)$. Panel c: zoom-in of MS fragmentation pattern of $\mathbf{2 b}$ with relevant peak for 2b (fragment 99 corresponding to fragmentation at ester bond). 

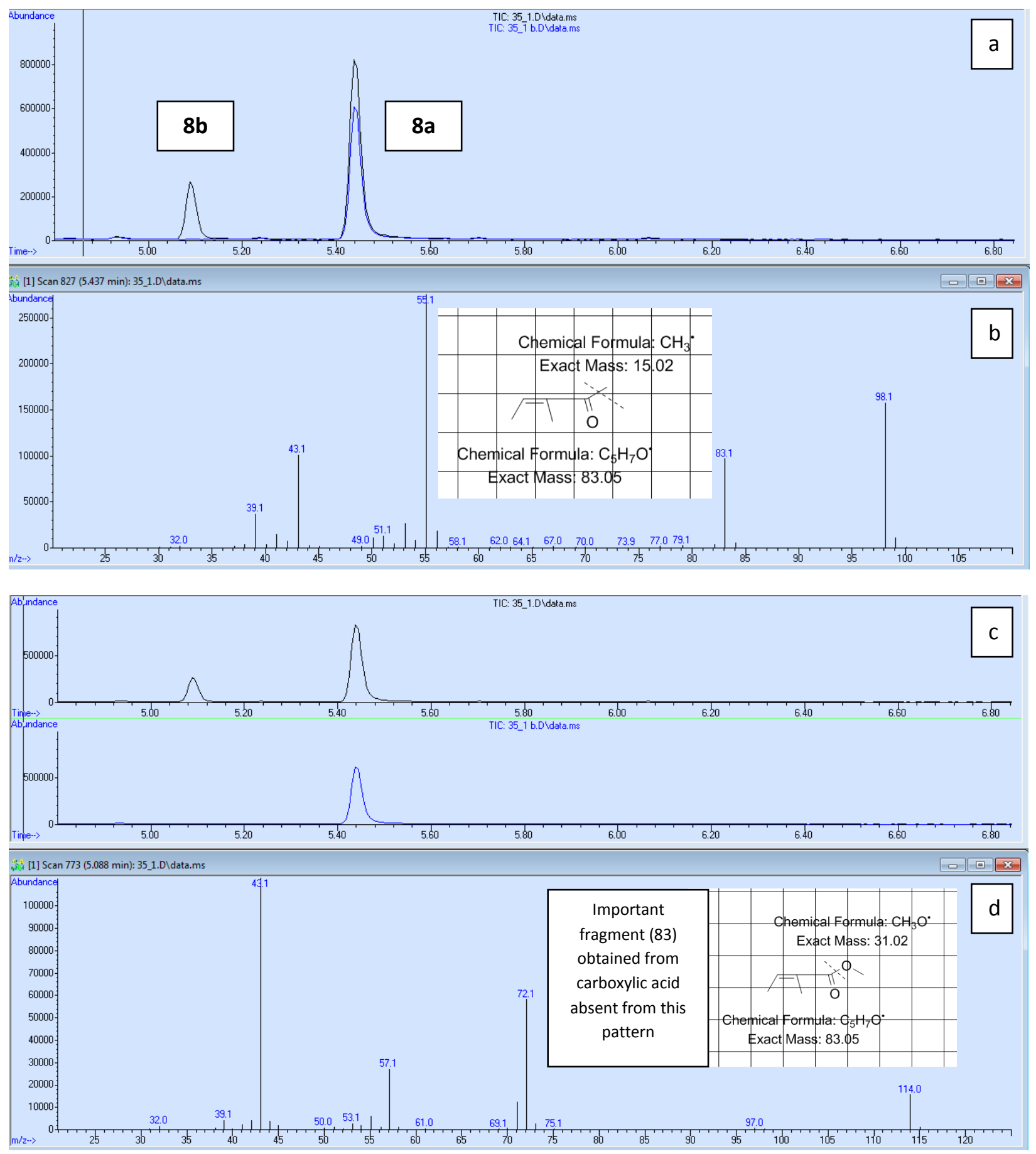

Spectrum overlay from GC-MS measurement of samples from blank (blue) and conversion of 8a (black). Panel a/c: GC traces showing $8 \mathbf{b}$ (retention time: $5.1 \mathrm{~min}$ ) and $8 \mathbf{a}$ (retention time: 5.4 min). Panel b: MS fragmentation pattern of 8a (MW 98 g.mol ${ }^{-1}$ ). Panel d: MS fragmentation pattern of $\mathbf{8 b}$ (MW 114 g.mol ${ }^{-1}$ ) with absence of relevant peak for 8a (fragment 83 corresponding to fragmentation after $\mathrm{C}=\mathrm{O}$ ) also present in carboxylic acid as displayed in insert. 

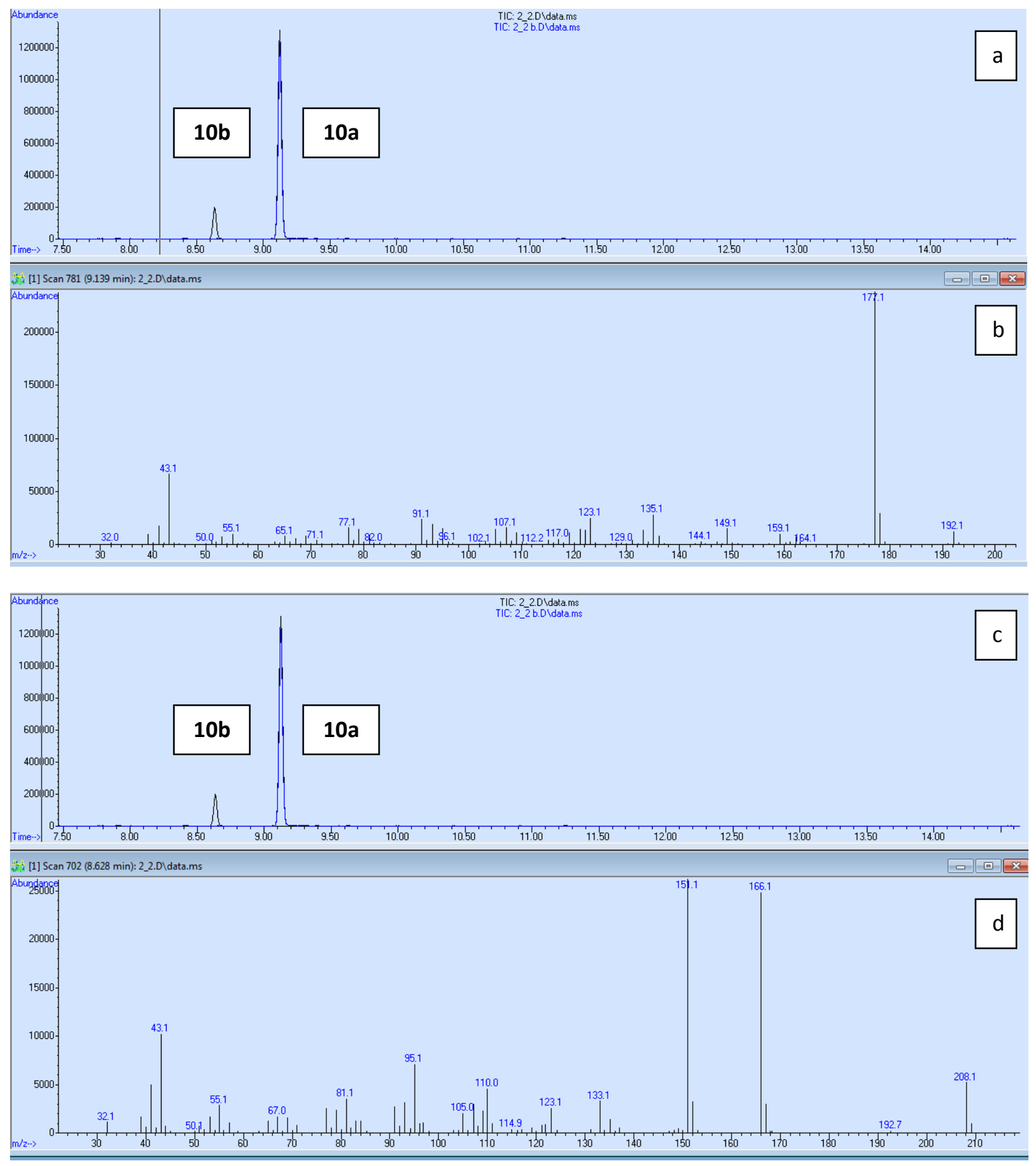

Spectrum overlay from GC-MS measurement of samples from blank (blue) and conversion of 10a (black). Panel a/c: GC traces showing 10b (retention time: $8.6 \mathrm{~min}$ ) and 10a (retention time: 9.1 min). Panel b: MS fragmentation pattern of 10a (MW 192 g.mol ${ }^{-1}$ ). Panel d: MS fragmentation pattern of $\mathbf{1 0 b}\left(\mathrm{MW} 208 \mathrm{~g}_{\mathrm{mol}}{ }^{-1}\right.$ ) with relevant peak for $\mathbf{1 0 b}$ (fragment 166 corresponding to fragmentation at ester bond). 


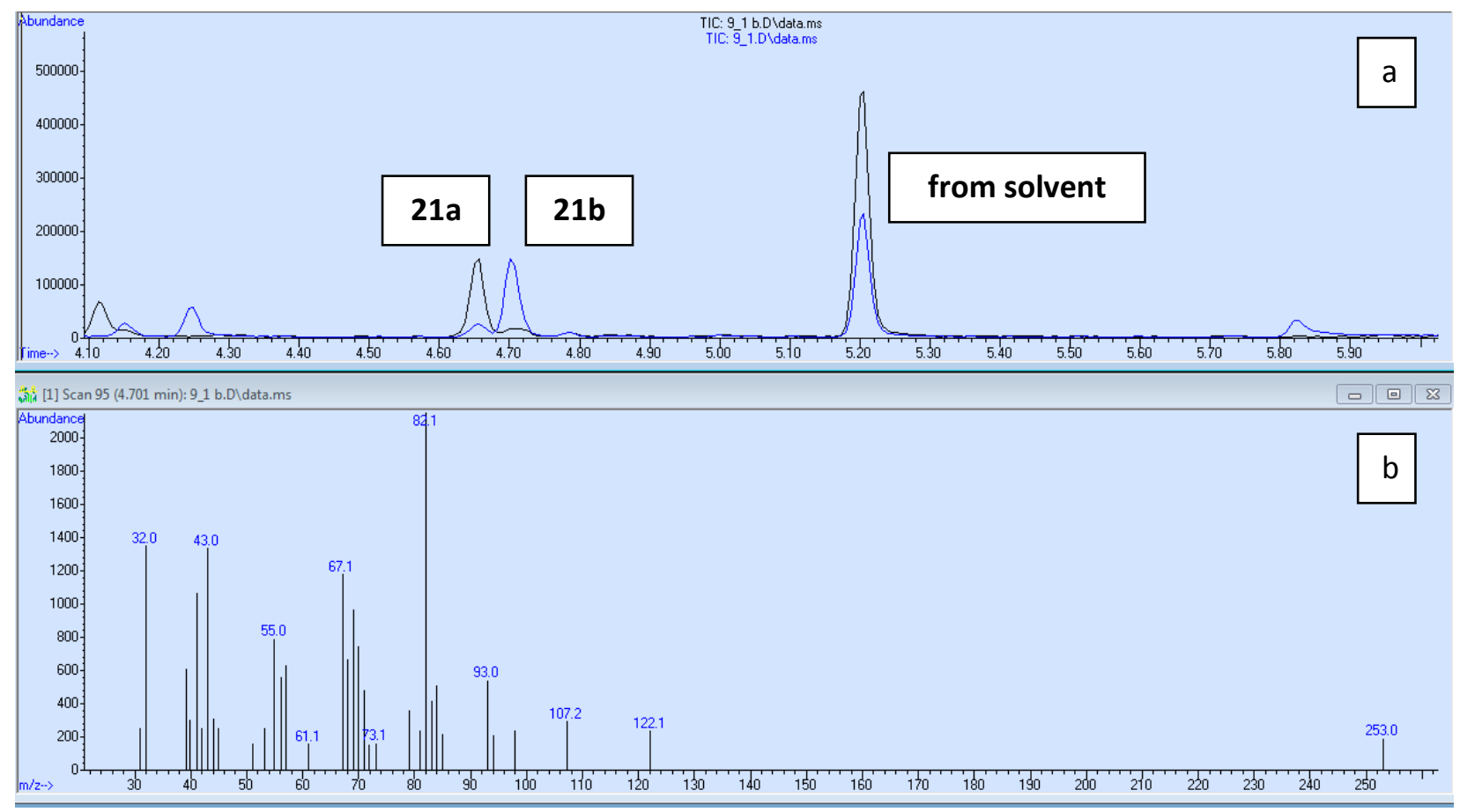

Spectrum overlay from GC-MS measurement of samples from blank (black) and conversion of 21a (blue). Panel a: GC traces showing 21a (retention time: $4.65 \mathrm{~min}$ ) and 21b (retention time: $4.70 \mathrm{~min})$. Panel b: MS fragmentation pattern of $\mathbf{2 1 b}$. 


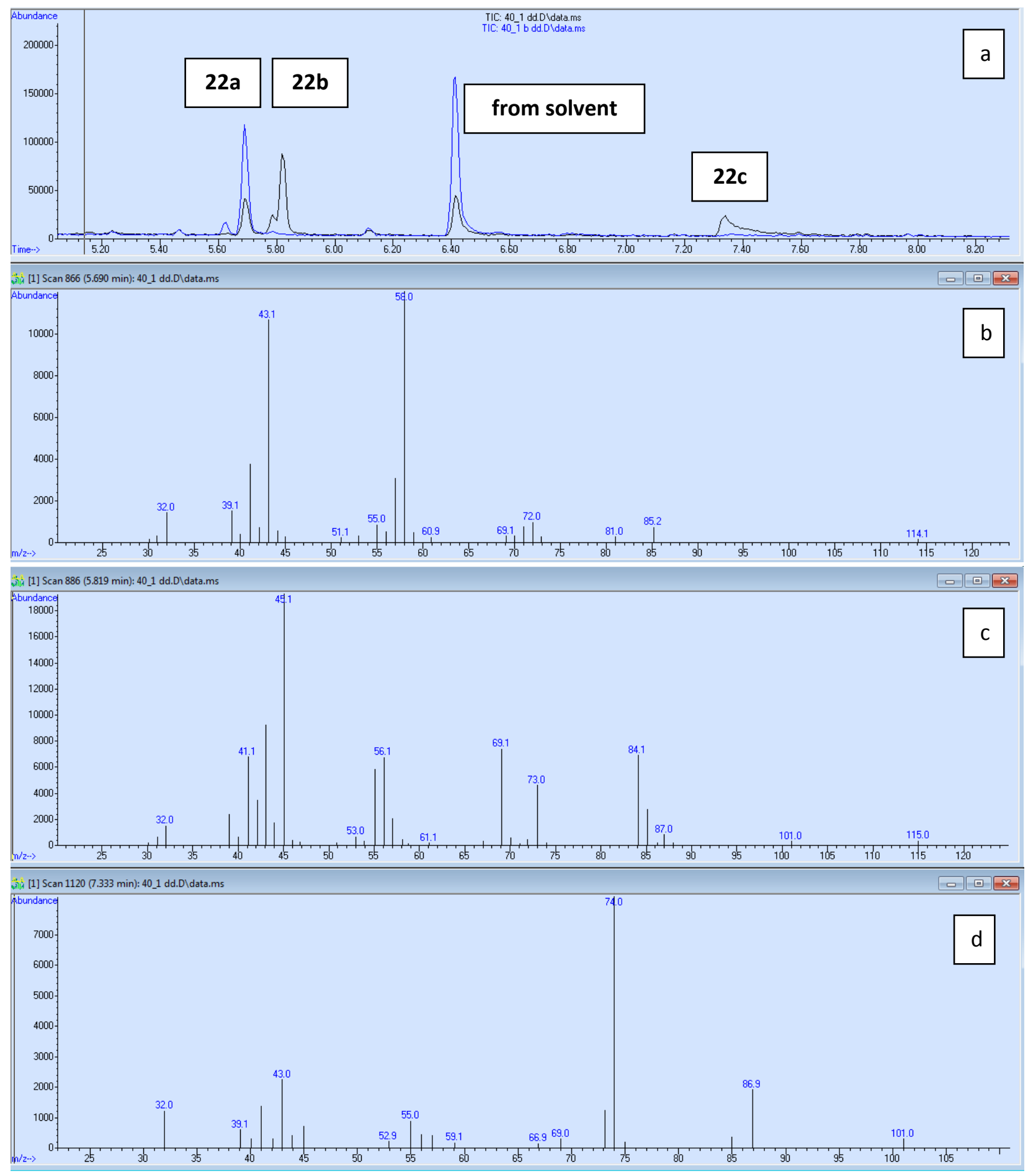

Spectrum overlay from GC-MS measurement of samples from blank (blue) and conversion of 22a (black). Panel a: GC traces showing 22a (retention time: $5.7 \mathrm{~min}$ ), 22b (retention time: 5.8 min) and 22c (retention time: $7.3 \mathrm{~min}$ ). Panel b: MS fragmentation pattern of 22a (MW 114 g.mol ${ }^{-1}$ ). Panel c: MS fragmentation pattern of 22b (MW 130 g.mol ${ }^{-1}$ ). Panel d: MS fragmentation pattern of 22c (MW $\left.130 \mathrm{~g} \cdot \mathrm{mol}^{-1}\right)$. 

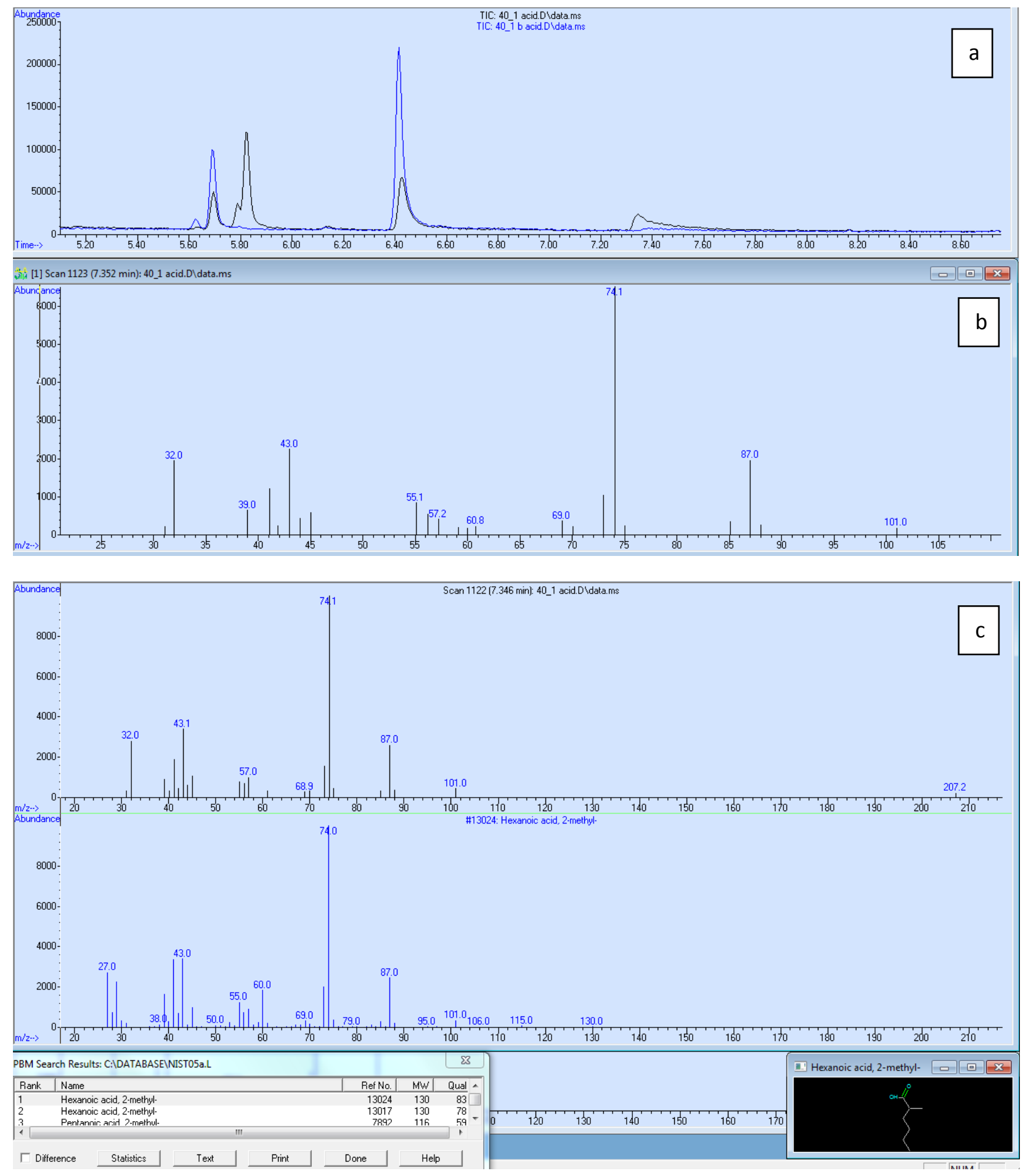

Spectrum overlay from GC-MS measurement of samples from blank (blue) and conversion of 22a (black) after acidic workup. Panel a: GC traces showing 22a (retention time: 5.7 min), 22b (retention time: $5.8 \mathrm{~min}$ ) and 22c (retention time: $7.3 \mathrm{~min}$ ). Panel b: MS fragmentation pattern of 22c (MW 130 g.mol ${ }^{-1}$ ). Panel c: MS fragmentation pattern of 22c compared to fragmentation pattern of authentic 22c showing high identity. 


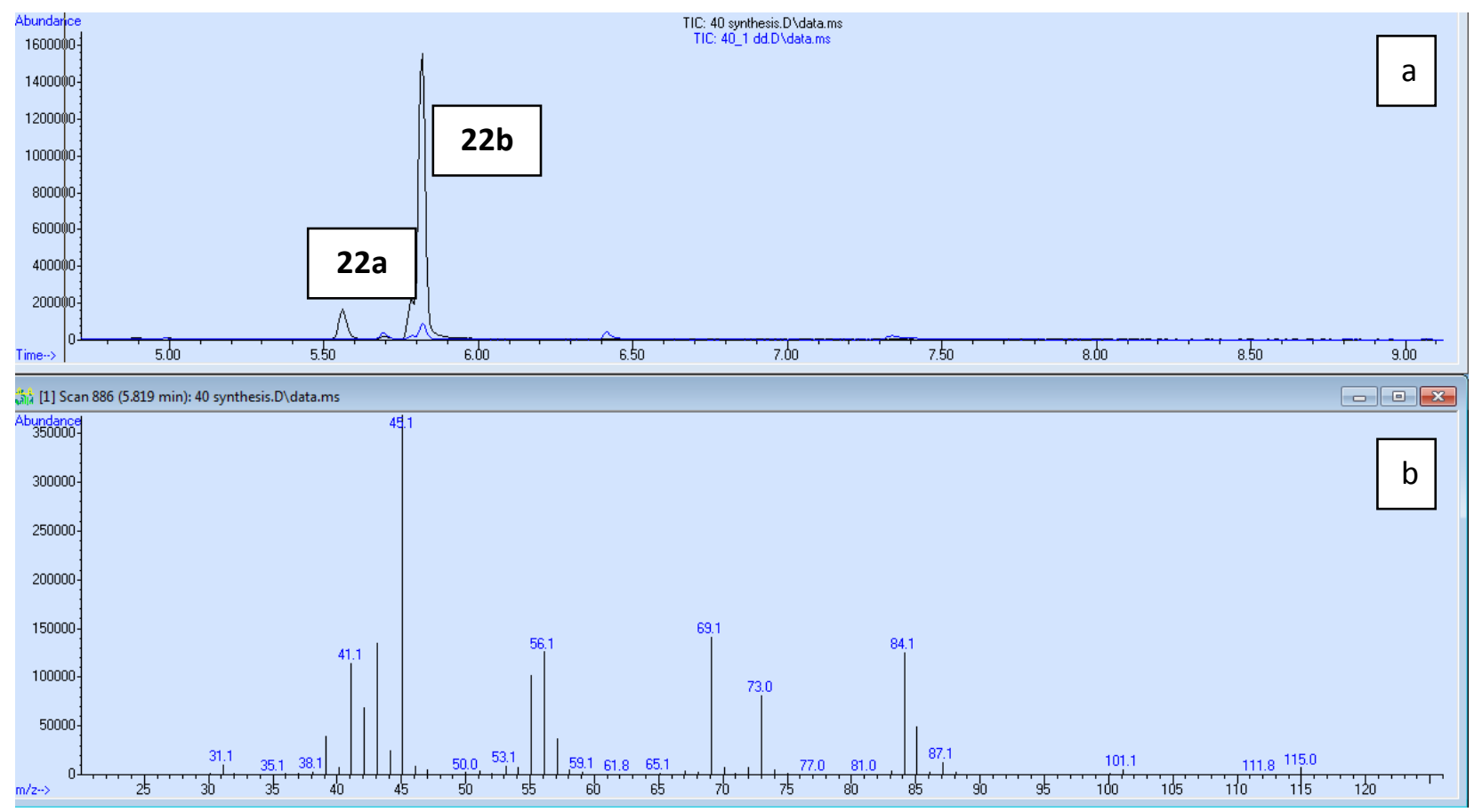

Spectrum overlay from GC-MS measurement of samples from FMO5-catalyzed reaction with 22a (blue) and chemical synthesis of 22b via $m$-CPBA Baeyer-Villiger reaction (black). Panel a: GC traces showing 22a (retention time: $5.7 \mathrm{~min}$ ), $\mathbf{2 2 b}$ (retention time: $5.8 \mathrm{~min}$ ) and 22c (retention time: $7.3 \mathrm{~min}$ ). Panel b: MS fragmentation pattern of chemically synthesized 22b (MW 130 g.mol ${ }^{-1}$ ), perfectly identical to that of enzymatically produced $\mathbf{2 2 b}$. 


\section{Protocol for synthesis of $22 \mathrm{~b}$ according to standard procedures}

To a solution of $22 \mathrm{a}\left(1.00 \mathrm{eq}, 1.8 \mathrm{mmol}, 0.2 \mathrm{M}\right.$ in $\mathrm{CH}_{2} \mathrm{Cl}_{2}$ ) was added $m$-CPBA (2.40 eq, 4.3 $\mathrm{mmol}, 0.75 \mathrm{~g}$ ) at $0{ }^{\circ} \mathrm{C}$. After stirring overnight at RT, the reaction mixture was quenched with 5 $\mathrm{ml}$ of $10 \% \mathrm{~K}_{2} \mathrm{CO}_{3}$ aquous solution and $5 \mathrm{ml}$ of a saturated aqueous solution of $\mathrm{Na}_{2} \mathrm{~S}_{2} \mathrm{O}_{3}$. The aqueous layer was separated and extracted with $\mathrm{CH}_{2} \mathrm{Cl}_{2}(2 \times 5 \mathrm{ml})$. The combined organic layer was dried $\left(\mathrm{Na}_{2} \mathrm{SO}_{4}\right)$, filtered and concentrated under reduced pressure. Analysis by GC-MS provided reference with enzymatic reaction. 


\section{REFERENCES}

1. Krueger, S.K.; Williams, D.E. (2005) Mammalian flavin-containing monooxygenases: structure/function, genetic polymorphisms and role in drug metabolism. Pharmacol. Ther. $106,357-387$.

2. Riebel, A.; de Gonzalo, G.; Fraaije, M.W. (2013) Expanding the biocatalytic toolbox of flavoprotein monooxygenases from Rhodococcus jostii RHA1. J. Molecular Catalysis B: Enzymatic 88, 20-25.

3. Riebel, A.; Fink, M.J.; Mihovilovic, M.D.; Fraaije, M.W. (2014) Type II flavin-containing monooxygenases: a new class of biocatalysts that harbors Baeyer-Villiger monooxygenases with a relaxed coenzyme specificity. ChemCatChem 6, 1112-17.

4. Fraaije, M.W.; Kamerbeek, N.M.; van Berkel, W.J.H.; Janssen, D.B. (2002) Identification of a Baeyer-Villiger monooxygenase sequence motif. FEBS Lett. 518, 43-47.

5. Valerio, V.; Petkova, D.; Madelaine, C.; Maulide, N. (2013) Direct room-temperature lactonisation of alcohols and ethers onto amides: an "amide strategy" for synthesis. Chem. Eur. J. 19, 2606-2610. 